${ }^{3}$ Bowes, G., Ogren, W. L., and Hageman, R. H., Biochem. Biophys. Res. Commun., 45, 716 (1971).

4 Andrews, T. J., Lorimer, G. H., and Tolbert, N. E., Biochemistry, 12, 11 (1973)

5 Lorimer, G. H., Andrews, T. J., and Tolbert, N. E., Biochemistry, 12, 18 (1973)

6 Andrews, T. J., Lorimer, G. H., and Tolbert, N. E., Biochemistry, 10,4777 (1971).

7 Goldsworthy, A., Nature, 224, 501 (1969).

8 Turner, J. S., and Brittain, E. G., Biol. Rev., 37, 130 (1962).

9 Bjorkman, O., in Photosynthesis and Photorespiration (edit. by Hatch, M. D., Osmond, C. B., and Slatyer, R. O.), 18 (Wiley, New York, 1971).

10 James, T. H., and Weissberger, A., J. Amer. Chem. Soc., 59, 2040 (1937).

13 Proske, B., thesis, Univ. of Heidelberg (1956).

12 Cramer, F., and Proske, B., Angew. Chem., 68, 120 (1956).

13 Hatch, M. D., and Slack, C. R., in Progress in Phytochemistry (edit. by Reinhold, L., and Liwschitz, Y.), 2, 35 (Interscience, London, 1970).

14 Volk, R. J., and Jackson, W. A., Plant Physiol., 49, 218 (1972).

15 Osmond, C. B., and Harris, B., Biochim. Biophys, Acta, 234, 270 (1971).

16 Huang, A. H. C., and Beevers, H., Plant Physiol., 50, 242 (1972).

17 Hatch, M. D., Biochem. J., 125, 425 (1971).

18 Ranson, S. C., and Thomas, M., Ann. Rev. Plant Physiol., 11, 81 (1960).

\section{Interspecific Hybridization in Cardium}

BOYDEN $^{1}$ has shown that cross-fertilization takes place between the cockles Cardium edule, Linné, and Cardium glaucum, Bruguière. He used, as the criteria for successful hybridization, either the production of rotating trochophores, still within the confines of the egg sheath, or free-swimming veligers; no attempts were made to rear the larvae.
Insemination was effected as soon after discharge as possible, thereby minimizing post-spawning deterioration effects.

Each experiment consisted of duplicate cultures - one pair with the intraspecific cross, one pair with the interspecific cross and one pair of control cultures in which no spermatozoa were added to the ova. Maintenance of control cultures of uninseminated ova was essential for two reasons. First, although the seawater used in the test cultures had been carefully membrane filtered, it was impractical to keep the adult stocks in water thus treated, so there was always the possibility of fertilization by unwanted spermatozoa already present in the water. Second, the occurrence of hermaphro ditic individuals is not unknown so the possibility of selffertilization could not be overlooked.

After incubation for 24-48 h, during which time the fertilized ova had undergone sufficient development to be easily recognized, 100-200 eggs were removed and examined to determine the numbers of fertilized and unfertilized eggs. Further development was then allowed to take place, the cultures being maintained in optimum conditions for growth.

The results of these cross-fertilization experiments are shown in Table 1. It becomes immediately apparent from these figures that cross-fertilization is possible between $C$. edule and $C$. glaucum, further substantiating the findings of Boyden ${ }^{1}$. Examination of the results, however, reveals that the success rate of the interspecific crosses is small when compared with the intraspecific fertilizations. Subsequent rearing of the hybrid larvae met with little success in most of the attempted crosses; in a single case, however (experiment 15), the larvae lived long enough to metamorphose into adults. In general, cross-fertilizations between species originating from a mixed population (for example, the River

Table 1 Percentage Success of Cross-fertilizations between Individuals Originating from: $a$, Geographically Distinct Populations; $b$, a Mixed Cockle Population

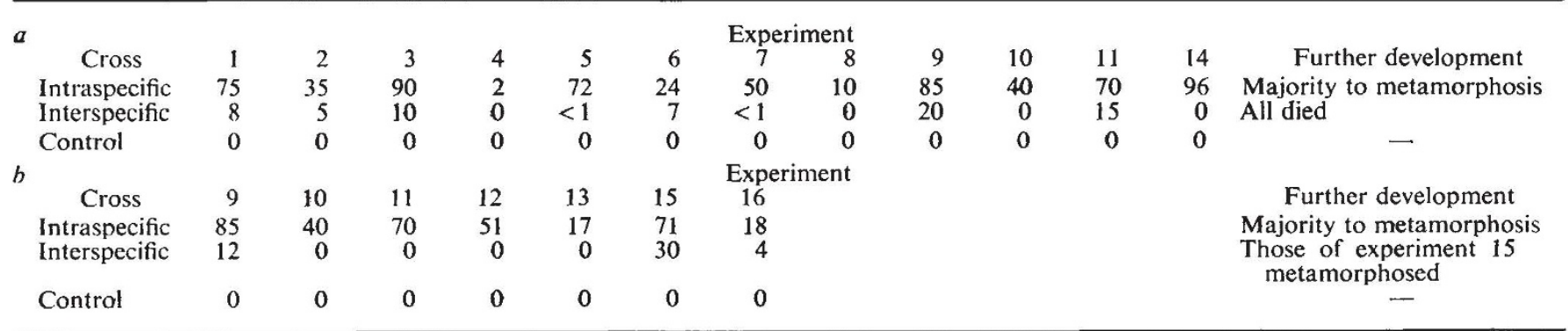

Female parent of interspecific crosses: experiments 1,2,5 and 6, C. edule; remaining experiments, C. glaucum.

Origin of individuals used in the experiments: C. edule, Shoeburyness, Essex; Ellanore, Chichester Harbour, W. Sussex; River Crouch, Essex; C. glaucum, Widewater, W. Sussex; River Crouch, Essex.

Galtsoff and $\mathrm{Smith}^{2}$ were able to cross-fertilize two oyster species, Crassostrea virginica and Crassostrea gigas, and obtained what appeared to be normal, healthy veliger larvae. Davis $^{3}$ also successfully cross-fertilized these two species of Crassostrea, but although the larvae appeared normal and vigorous in behaviour, none survived beyond the tenth day of development.

A recently developed method of reliably rearing the larvae of $C$. edule and $C$. glaucum through to metamorphosis has enabled fully controlled cross-fertilizations to be conducted in the laboratory. This allows not only the determination of the success rate of cross-fertilization, but also the ability of the resultant larvae to survive.

Unfertilized ova and spermatozoa were obtained by inducing isolated, sexually mature cockles of both species to spawn in the laboratory. The experimental cross-fertilizations were carried out in $250 \mathrm{ml}$ tall-form beakers, in which 5,000 to 8,000 ova were inseminated, using $1.5 \mathrm{ml}$ of spermatozoa suspension prepared by diluting the entire produce of a single male in $500 \mathrm{ml}$ of sterile seawater. The ova used in all the experiments were the results of normal spawning and in no cases were artificially stripped ova used.
Crouch) tended to be less successful than crosses between species from different geographic locations. The poor survival of hybrid larvae is of particular significance, especially in mixed cockle populations where it could result in the reduction of the reproductive capability of the two component species.

In mixed populations, individuals bearing apparent intermediate morphological characteristics do occur. Although limited, the successful rearing of hybrid larvae suggests that these intermediates are in fact true hybrids, and that their morphology is determined genetically and not simply as the result of environmental influence.

I thank Dr David Urry for help. This work was conducted during the tenure of a research studentship at the Hatfield Polytechnic.

P. KINGSTON

Dove Marine Laboratory,

Cullercoats, Northumberland

Received January 24; revised March 21, 1973.

1 Boyden, C. R., J. Mar. Biol. Ass. UK, 51, 605 (1971).

2 Galtsoff, P. S., and Smith, R. O., Science, 76, 371 (1932).

3 Davis, H. C., Science, 111, 522 (1950). 